\title{
Tubal Ektopik Gebelik Tanısında Tam Kan Sayımı Parametrelerinin Değerlendirilmesi
}

\section{Evaluation of Complete Blood Count Parameters in Tubal Ectopic Pregnancy}

\author{
Gökçe TURAN 1 일
}

\author{
1 Gazi Üniversitesi Tıp Fakültesi, Kadın Hastalıkları ve Doğum Anabilim Dalı, Ankara, Türkiye \\ 2 Sağlık Bilimleri Üniversitesi İstanbul Kanuni Sultan Süleyman Eğitim ve Araştırma Hastanesi, Kadın Hastalıkları ve Doğum \\ Kliniği, İstanbul, Türkiye \\ 3 Tekirdağ Devlet Hastanesi, Kadın Hastalıkları ve Doğum Kliniği, Tekirdağ, Türkiye \\ 4 Dicle Universitesi Tıp Fakültesi, Kadın Hastalıkları ve Doğum Anabilim Dalı, Diyarbakır, Türkiye
}

Öz.

Amaç: Bu çalışmadaki amaç ektopik gebeliği (EG) olan hastalar ile sağlıkı intrauterin gebeliği olan hastaların hemogram parametrelerini karşılaştırmaktır.

Materyal ve Metod: Ocak 2013 ile Ocak 2017 tarihleri arasında tersiyer bir merkezde tubal EG tanısı konan hastalar ile ilk trimester intrauterin gebeliği olan hastaların demografik verileri ve tam kan sayımındaki beyaz küre (WBC), hemoglobin ( $\mathrm{Hgb})$, hematokrit (Hct), nötrofil, lenfosit, platelet (PLT), ortalama platelet hacmi (MPV), nötrofil-lenfosit oranı (NLO) ve platelet-lenfosit oranı (PLO) karşılaştırıldı.

Bulgular: EG'i olan 718 hasta ile sağlıklı intrauterin gebeliği olan 937 hasta çalışmaya dahil edildi. Yaş, gravida, parite ve abortus EG grubunda (çalışma grubu) anlamlı olarak daha yüksek izlenirken ( $p<0,001)$, gestasyonel hafta ise kontrol grubunda anlamlı olarak yüksek bulundu $(p<0,001)$. $\mathrm{Hgb}$, Hct ve MPV değerleri kontrol grubunda anlamlı olarak yüksek izlenirken ( $p<0,001)$, WBC, PLT, NLO ve PLO değerleri karşılaştıııldığında iki grup arasında anlamlı fark izlenmedi. Sonuç: Sonuç olarak EG'i öngörmede hemogram parametrelerinden sadece MPV değeri anlamlı bulundu. Bu çalışmada NLO ve PLO değerleri EG tanısında anlamlı bulunmadı. EG tanı ve tedavi protokollerinde hemogram, NLO ve PLO değerleri daha olası ilişkileri araştırmak için daha geniş hasta gruplarının inceleneceği prospektif çalışmalara ihtiyaç vardır.

Anahtar Kelimeler: Ektopik gebelik, Ortalama platelet hacmi, Nötrofil-lenfosit oranı, Platelet-lenfosit oranı.

\section{Abstract}

Background: The aim of this study was to compare the hemogram parameters of patients with ectopic pregnancy (EP) and healthy intrauterine pregnancy.

Materials and Methods: Between January 2013 and January 2017, the demographic data of patients with first-trimester intrauterine pregnancy and patients with a diagnosis of tubal EP issue in a tertiary center, and white blood cell count (WBC), hemoglobin (Hgb), hematocrit (Hct), neutrophil and lymphocyte count, neutrophil-lymphocyte ratio (NLR), platelet count (PLT), platelet lymphocyte ratio (PLR) and mean platelet volume (MPV) values on complete blood count were recorded and compared with each other.

Results: A total of 718 patients with ectopic pregnancies and 937 patients with healthy intrauterine pregnancies were included in the present study. Between groups, age, gravida, parity, and abortion in the group with EP (study group) were monitored significantly higher $(p<0.001)$, the gestational week was found significantly higher in the control group $(p<0.001) . H g b, \mathrm{Hct}$ and MPV values of the groups were monitored significantly higher in the Control Group $(p<0.001)$, and no significant differences were detected between the WBC, PLT, NLR and PLR values of both groups.

Conclusions: As a result, only the MPV value was found significant among the hemogram parameters in predicting ectopic pregnancy. In this study, NLR and PLR values were not found significant in the diagnosis of EP. Prospective studies with larger participants are needed to investigate more possible relationships with hemogram, NLR and PLR values in EP diagnosis and treatment protocols.

Key words: Ectopic pregnancy, Mean platelet volume, Methotrexate, Neutrophil lymphocyte ratio, Platelet-tolymphocyte ratio

\section{Sorumlu Yazar I \\ Corresponding Author}

Dr. Gökçe Turan

Gazi Üniversitesi Tıp Fakültesi, Kadın Hastalıkları ve Doğum

Anabilim Dalı,

Ankara, Türkiye

Tel: +905336745074

e mail: drgokceturan@gmail.com

Geliş tarihi / Received:

19.12.2019

Kabul tarihi / Accepted: 09.03.2020

DOI: 10.35440/hutfd.661424 


\section{Giriş}

Ektopik gebelik (EG) fertilize olmuş ovumun endometriyal kavite dışında başka bir yere implante olmasıdır. İnsidansı 1/150-1/1000 arasında değişmektedir (1) . EG en sık tubalarda oluşmaktadır ve tubal EG'in de en sık implantasyon yeri ampulladır (2). Bilinen en sık risk faktörleri; geçirilmiş tubal cerrahiler, daha önce EG geçirmiş olmak, enfeksiyon kaynaklı tubal hasar, sigara ve yardımcı üreme teknikleridir (3). Sitokinler, integrinler ve büyüme faktörlerinin EG patogenezinde rol oynayabileceği ve bu faktörlerin transport bozukluğu nedeniyle erken implantasyona yol açabileceği belirtilmiştir (4). Bu büyüme faktörleri ile birlikte hemogram parametrelerinin de EG tanısındaki rolü araştırımaya başlanmıştır. Ortalama platelet hacmi (MPV) ve lökosit sayısında artışın EG'i öngörmede etkili olabileceği bildirilmiştir (5). Bunun aksine hem tubal hem de rüptüre EG'te MPV'de düşüş olduğu ve EG'in patogenezinde inflamasyonun rol oynayabileceği ileri sürülmüştür $(6,7)$.

EG ve enflamatuar süreç üzerine yapılan bazı çalışmalarda, trombosit sayısı (PLT), trombosit dağılım genişliği (PDW) ve nötrofil lenfosit oranı (NLO) gibi belirteçlerin seviyelerinde bir artış olduğunu ortaya koymuş ve bu belirteçlerin EG'te tedavinin takibi ve cerrahi gereksinimin belirlenmesinde yardımcı olabileceği bildirilmiştir (8).

Bu çalışmadaki amaç EG'i olan hastalar ile sağlıklı intrauterin gebeliği olan hastaların hemogram parametrelerini karşılaştırmaktır..

\section{Materyal ve Metod}

0 Ocak 2013 ile Ocak 2017 tarihleri arasında tersiyer bir merkezde tubal EG tanısı konan hastalar ile ilk trimester intrauterin gebeliği olan hastaların kayıtları retrospektif olarak incelendi. Çalışma öncesi etik kurul onayı alındı (Sağlık Bilimleri Üniversitesi Bakırköy Dr. Sadi Konuk Eğitim ve Araştırma Hastanesi, etik kurul no: 2017/415). Çalışma grubu olarak tubal ektopik odak saptanan, başvuru sırasında tubal rüptür bulunmayan hastalar dahil edilirken, servikal, ovaryan veya skar EG'ler, lokasyonu bilinmeyen EG'i olan hastalar, myoma uterisi olan, ek sistemik hastalığı olan, sigara içen, antikoagülan ilaç kullanan hastalar çaıışma dışı bırakıldı. Aynı tarihler arasında polikliniğe başvuran ilk trimester gebelik haftalarında intrauterin gebeliği olup fetal kalp atımı görülen ve miadında sağlıklı doğum yapan hastalar kontrol grubuna dahil edildi. Gebelik sürecinde gestasyonel diyabet (GDM), preeklampsi, erken membran rüptürü ve preterm doğum gibi komplike gebelikler kontrol grubuna dahil edilmedi.

EG tespit edilen hastaların tümüne Metotreksat (MTX) tedavisi uygulandı. MTX tedavisi uygulananan hastalar; başlangıç $\beta$ hCG değerleri $<10.000 \mathrm{mlU} / \mathrm{ml}$, tubal ektopik odak boyutu $4 \mathrm{~cm}$ 'in altında, rüptüre olmamış ve fetal kardiak aktivitenin izlenmediği, aktif hepatik veya renal hastalığı bulunmayan tubal EG'lerdi. Medikal tedavide tek doz intramuskuler (im) Metotreksat (MTX) protokolü uygulandı (9).
Uygulama sonrası $\beta$-HCG değerleri, MTX dozunun uygulandığı 4 ve 7 . günlerde tekrar edildi. 4. ve 7. günler arasında $\% 15$ 'den daha fazla bir azalma varlı̆ıında, tüm olgular haftalık takipler ile, $\beta$-HCG değerleri $5 \mathrm{IU} / \mathrm{ml}$ 'nin altına düşene kadar izlendi ve bu olgular MTX başarılı grup olarak değerlendirildi. MTX tedavisine cevap vermeyen veya MTX tedavisi sırasında rüptüre olan hastalara ise laparoskopi veya laparotomi ile cerrahi tedavi uygulandı ve bu hastalar ise MTX başarısız grup olarak kabul edildi.

EG'i olan hastalar ile intrauterin sağlıklı gebeliği olan hastaların yaş, gravida, parite, abortus gibi demografik verileri kaydedildi ve birbirleri ile karşılaştıııld. Her iki gruptan da tam kan sayımı yapıldı. Tam kan sonuçları hastanemizin veri tabanından retrospektif olarak incelendi ve WBC, $\mathrm{Hgb}$, Hct, nötrofil ve lenfosit değerleri, NLO, PLT, platelet lenfosit oranı (PLO) ve MPV değerleri kaydedilerek birbirleri ile karşılaştırıldı. Ayrıca çalışma grubundaki hastalar MTX başarılı ve MTX başarısız ektopik gebelik olarak 2'ye ayrıldı ve hem demografik verileri hem de hemogram parametreleri kendi aralarında alt grup olarak karşılaştıılı. Tüm kan numuneleri EG tespit edilen hastalarda MTX tedavisi başlanmadan önce, sağlıklı gebelerde ise fetal kalp atımı görülen ilk muayene sırasında alındı, EDTA (potasyum) tüplerde toplandı (antikoagülan madde olarak görev yapan etilendiamintetraasetat) ve hematoloji analizörü tarafından analiz edildi.

Çalışmanın istatistiksel analizinde Statistical Package for Social Sciences 20.0 (SPSS Inc.; Chicago, IL, USA) programı kullanılarak yapıldı. Verilerin dağılımı KolmogorovSmirnov testi ile değerlendirildi. Normal dağılan verilerin değerlendirilmesinde tanımlayıcı istatistiksel metotların (ortalama, standart sapma) yanı sıra ikili grupların karşılaştırmasında bağımsız t-testi kullanıldı. Sonuçlar, anlamılıık $p<0,05$ düzeyinde değerlendirildi. ROC analizinde MPV cut-off değeri, sensitivite ve spesifitesi hesaplandı.

\section{Bulgular}

Çalışmaya toplam 1655 hasta dahil edildi. Hastalar sağıklı intrauterin gebeler ve tubal non-rüptüre EG olmak üzere iki gruba ayrıldı. Kontrol grubunda 718 sağlıklı intrauterin hasta mevcutken, çalışma grubunda 937 tubal non-rüptüre EG vardı. EG tespit edilen hastaların (n:937) tümüne tek doz MTX tedavisi uygulandı. Bu hastalardan 655 'inde (\%69.9) tek doz MTX tedavisi başarılı iken, 282 (\%30.1) hastada ise MTX tedavisine cevap alınamadığından veya tedavi sırasında rüptür gelişmesi nedeni ile MTX tedavisi başarısız olup cerrahi uygulandı. EG ve intrauterin sağlıklı gebeliği olan hastaların demografik verileri Tablo-1'de listelendi. Yaş, gravida, parite ve abortus değerleri EG'i olan grupta anlamlı olarak daha yüksek izlenirken $(p<0,001)$, gestasyonel hafta kontrol grubunda anlamlı olarak daha yüksek bulundu $(p<0,001)$. Her iki grubun hemogram parametreleri ve NLO, PLO değerleri Tablo-2'de gösterilmiştir. $\mathrm{Hgb}, \mathrm{Hct}$ ve MPV değerleri kontrol grubunda anlamlı olarak 
daha fazla izlenirken $(p<0,001)$, WBC, PLT, NLO ve PLO değerleri karşılaşıırıldığında iki grup arasında anlamlı fark izlenmedi. Ayrıca EG olan hastalar MTX başarılı ve MTX başarısız olarak 2'ye ayrıldığında elde edilen demografik veriler Tablo-3'te listelenmiştir. Grupların demografik verileri arasında anlamlı fark izlenmedi. MTX başarısız grubun $\mathrm{Hgb}$ ve Hct değerleri MTX başarılı gruba göre anlamlı olarak daha düşük iken $(p<0,001), M P V, W B C, P L T, N L O$ ve PLO parametreleri arasında istatistiksel olarak fark izlenmedi (Tablo-4).

Tablo 1. Ektopik ve Sağlıklı Gebelerin Demografik Verilerinin Karşılaştırılması

\begin{tabular}{llll}
\hline & $\begin{array}{l}\text { Ektopik gebelik } \\
(\text { mean } \pm S D)(n: 937)\end{array}$ & $\begin{array}{l}\text { Intrauterin gebelik } \\
(\text { mean } \pm S D)(n: 718)\end{array}$ & $\begin{array}{l}\mathbf{P} \\
\text { değeri }\end{array}$ \\
\hline Yaş & $30,230 \pm 5,676$ & $27,940 \pm 5,798$ & $<0,001$ \\
Gravida & $3,037 \pm 1,646$ & $2,468 \pm 1,421$ & $<0,001$ \\
Parite & $1,340 \pm 1,155$ & $1,159 \pm 1,153$ & $<0,001$ \\
Abortus & $0,617 \pm 1,006$ & $0,301 \pm 0,679$ & $<0,001$ \\
Gestasyonel & $6,645 \pm 1,754$ & $7,401 \pm 1,836$ & $<0,001$ \\
hafta & & & \\
\hline
\end{tabular}

Tablo 2. Ektopik ve Sağ|ıklı Gebelerin Laboratuvar Değerlerinin Karşılaştırıması

\begin{tabular}{|c|c|c|c|}
\hline & $\begin{array}{l}\text { Ektopik } \\
\text { (mean } \pm S D)(n: 937)\end{array}$ & $\begin{array}{l}\text { İntrauterin gebelik } \\
\text { (mean } \pm S D)(n: 718)\end{array}$ & $\begin{array}{l}\mathbf{P} \\
\text { değeri }\end{array}$ \\
\hline $\begin{array}{l}\text { WBC } \\
(\mathrm{K} / \mu \mathrm{l})\end{array}$ & $9,947 \pm 3,784$ & $9,621 \pm 5,313$ & 0,061 \\
\hline $\begin{array}{l}\mathrm{Hgb} \\
(\mathrm{g} / \mathrm{dl})\end{array}$ & $11,626 \pm 1,607$ & $12,334 \pm 1,093$ & $<0,001$ \\
\hline Hct (\%) & $35,210 \pm 4,638$ & $37,787 \pm 3,156$ & $<0,001$ \\
\hline $\begin{array}{l}\text { PLT } \\
(\mathrm{K} / \mu l)\end{array}$ & $253,965 \pm 68,872$ & $255,448 \pm 62,757$ & 0,602 \\
\hline $\begin{array}{l}\text { MPV } \\
\text { (fl) }\end{array}$ & $7,944 \pm 1,479$ & $9,623 \pm 1,862$ & $<0,001$ \\
\hline NLO & $3,983 \pm 3,835$ & $3,159 \pm 1,328$ & 0,411 \\
\hline PLO & $372,994 \pm 5357,685$ & $125,175 \pm 42,600$ & 0,310 \\
\hline
\end{tabular}

Hgb: hemoglobin; MPV: ortalama platelet hacmi; PLO: platelet-lenfosit oranı; PLT: platelet; NLO: nötrofil-lenfosit oranı; WBC: beyaz küre

Tablo 3. MTX Başarılı Olan ve Başarısız Olan Grupların Demografik Verilerinin Karşılaştırıması

\begin{tabular}{llll}
\hline $\begin{array}{l}\text { Demografik } \\
\text { veriler (mean } \pm \text { SD) }\end{array}$ & $\begin{array}{l}\text { MTX başarılı } \\
(\mathbf{n}: 655)\end{array}$ & $\begin{array}{l}\text { MTX başarısız } \\
(\mathbf{n}: \mathbf{2 8 2})\end{array}$ & P değeri \\
\hline Yaş & $30 \pm 6$ & $30 \pm 5,8$ & 0,522 \\
Gravida & $3 \pm 1,6$ & $3,1 \pm 1,7$ & 0,507 \\
Parite & $1,3 \pm 1,2$ & $1,3 \pm 1,1$ & 0,931 \\
Abort & $0,6 \pm 1$ & $0,6 \pm 1$ & 0,277 \\
Gestasyonel hafta & $6,6 \pm 1,7$ & $6,6 \pm 1,7$ & 0,385 \\
\hline
\end{tabular}

Tablo 4. MTX Başarılı Olan ve Başarısız Olan Grupların Laboratuvar Değerlerinin Karşılaştıııması

\begin{tabular}{llll}
\hline Değerler & $\begin{array}{l}\text { MTX başarılı } \\
\text { (n:655) }\end{array}$ & $\begin{array}{l}\text { MTX başarısız } \\
\text { (n:282) }\end{array}$ & P değeri \\
\hline WBC $(\mathrm{K} / \mu \mathrm{l})$ & $9,8 \pm 3,8$ & $10 \pm 3,7$ & 0,117 \\
$\mathrm{Hgb}(\mathrm{g} / \mathrm{dl})$ & $11,7 \pm 1,6$ & $11,4 \pm 1,5$ & $<0,001$ \\
$\mathrm{Hct}(\%)$ & $35,8 \pm 4,7$ & $34,6 \pm 4,4$ & $<0,001$ \\
PLT $(\mathrm{K} / \mu \mathrm{l})$ & $250,1 \pm 68,8$ & $255,7 \pm 68,7$ & 0,08 \\
MPV $(\mathrm{fl})$ & $7,9 \pm 1,4$ & $7,9 \pm 1,5$ & 0,4 \\
NLO & $4,09 \pm 3,8$ & $3,88 \pm 3,81$ & 0,055 \\
PLO & $328 \pm 4234$ & $417 \pm 6281$ & 0,078 \\
\hline
\end{tabular}

Hgb: hemoglobin; MPV: ortalama platelet hacmi; PLO: platelet-lenfosit oranı; PLT: platelet; NLO: nötrofil-lenfosit oranı; WBC: beyaz küre

Şekil-1'deki ROC eğrisinde EG'i ve intrauterin sağlıklı gebeliği olan hastalar arasında MPV değeri için eğri altındaki alan 0,768 'dir ve youden indeksine göre cut-off noktası 5,9 alındığında sensitivite \%74.6, spesifite \%89.7 (\%95 Cl: 0.733-0.890) olarak hesaplandı.

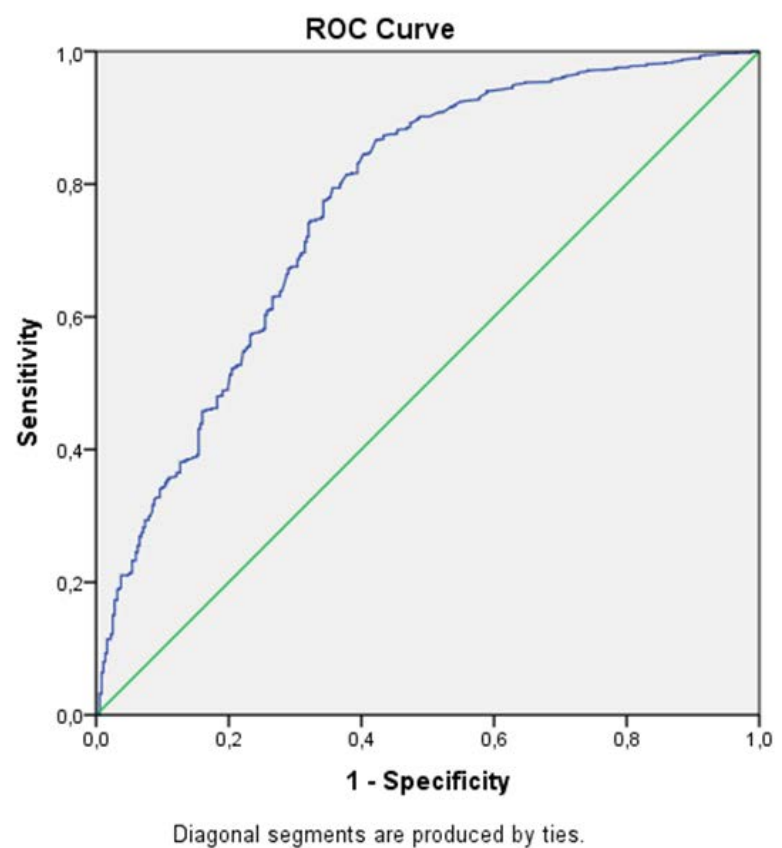

Şekil 1. Grupların MPV Değeri için ROC Eğrisi

\section{Tartışma}

Bu çalışmada EG ile sağlıklı ilk trimester intrauterin gebeliği olan hastaların hemogram parametreleri karşılaştıııldğında her iki grubun WBC, PLT, NLO, PLO değerleri arasında anlamlı fark bulunmazken, kontrol grubunun $\mathrm{Hgb}$, Hct ve MPV değerleri çalışma grubuna göre istatistiksel anlamlı yüksek tespit edildi. Tedavi başarısına göre kıyaslandığında; MTX başarısız grubun Hb ve Hct değerleri MTX başarılı gruba göre anlamlı olarak daha düşük iken, MPV, WBC, PLT, NLO ve PLO parametreleri arasında istatistiksel olarak fark izlenmedi.

$E G$, ilk trimester anne ölümlerinin yaygın bir sebebidir ve günümüzde artan yardımcı üreme teknikleri ile birlikte maternal morbiditenin artmasına neden olmaktadır (10). EG'te gecikmiş tanı, infertiliteyi olumsuz etkilemekle beraber tubal rüptür ve kanamaya neden olarak mortaliteye neden olmaktadır (11).

EG'in fizyopatolojisinde tubal transportun bozulması yer almaktadır. Ayrıca hipoksi ile aktifleşen anjiogenezisin oluşması, tubal muskuler tabakadaki inflamasyon nedenli değişim ve yine inflamasyon nedenli tubal mikroçevrenin bozulması da diğer nedenler olarak rapor edilmiştir (3). Ektopik odak tubal kanalda invazyon yaparak düz kas hasarına neden olur ve bunun sonucunda kreatin kinaz yükselir. Ayrıca uterus kadar fazla kanlanması olmamasına rağmen tubada implantasyon sonucu anjiogenezis olmasından dolayı Vasküler endotelyal büyüme faktörü artar (12). İnflamasyon parametreleri olan interlökin (IL)-6 ve 8, tümör nekrozis faktör (TNF)-alfa da EG'te yükselmektedir. Tüm 
bu markerlar inflamasyon ile ilişkilidir. Ancak yine de EG tanısında primer olarak kullanılmamaktadır. Bu çalışmada ise hemogram parametreleri incelenmiş ve EG tanısında etkinliği araştırılmıştır. Etyolojide tüm bu inflamasyon ile ilgili markerların yüksek bulunması, hemogram parametrelerine de yansıyarak EG tanısında etkili olabileceğini akla getirmektedir. Benzer şekilde yapılan bir çalışmada preeklamptik gebelerde (13) NLO ve MPV seviyelerinin sağlıklı gebelere göre yüksek olduğu ve bunun da enflamatuar süreç ile ilişkili olduğu bildirilmiş̧ir. Bu çalışmada preeklampsi, GDM gibi ek hastalıkların başı başına inflamasyona neden olabileceğinden kontrol grubundaki hastalar miada kadar takip edilmiş ve gebelik takibi boyunca preeklampsi veya GDM olan hastalar bu nedenle çalışma dışı bırakılmıştır.

Yakın zamanda yapılan tubal EG'i olan 138 hasta ile sağlıklı gebeliği olan 72 hastanın hemogram parametrelerinin karşılaştırıldığı bir çalışmada, tubal EG'i olan hastalarda sağ|ıklı gebelere göre PLT seviyelerinin daha düşük, monosit seviyelerinin ise daha yüksek olduğu bulunmuştur. EG'i olan hastalarda monosit yüksekliğinin tubal motilitenin bozulmasında etkili olabileceği bildirilmiştir (14). Bu çalışmada ise hem ektopik gebeliği ve sağlıklı intrauterin gebeliği olan hastaların PLT değerlerinde, hem de MTX başarılı ve başarısız olan grupların PLT değerleri karşılaştırıldığında anlamlı fark izlenmedi.

6-8 hafta arası 112 intrauterin sağıklı gebe ile 97 EG'nin hemogram parametrelerinin karşılaştırıldığı başka bir çaIışmada MPV değeri EG grubunda düşük iken, NLO yüksek bulunmuştur (15). Sağlıkı gebeler, non-rüptüre tubal EG'i olanlar ve rüptüre tubal EG'i olan hastaların MPV ve WBC değerlerinin karşılaştırıldığı başka bir çalışmada EG'i olanlarda MPV yüksek tespit edilirken, rüptüre olanlar ile non-rüptüre EG'ler kendi aralarında kıyaslandığında MPV değerleri arasında fark bulunmamıştır (5). Aynı çalışmada WBC değerlerine bakıldığında ise WBC rüptüre EG grubunda en yüksek seviyede bulunmuştur (5). Öte yandan, başka bir çalışmada tubal EG'te sağlıkı illk trimester gebelere göre MPV düzeyleri düşük bildirilmiştir (6). Bu çalışmadaki MPV değerleri önceki iki çalışmaya kıyasla sağlıklı gebelik grubunda daha yüksek tespit edildi. Ancak her iki çalışmadaki hastaların gebelik haftaları bu çalışma ile benzer olsa da, hasta sayıları bu çalışmaya göre daha azdı. MPV değerinin EG grubunda daha düşük bulunmasının nedeni bu farklııktan kaynaklanmış olabilir. Ayrıca başka bir çalışmada düşük doz inflamasyon sürecinde MPV seviyelerinin düştüğü, yüksek düzeydeki enflamatuar bozukluklarda MPV değerlerinde artış olduğu gösterilmiştir (16). Benzer şekilde bu çalışmada da MPV değerinin EG grubunda düşük bulunmasının nedeni, EG'te oluşan düşük dereceli inflamasyonun ve hipoksinin MPV değerlerinde düşmeye neden olması olabilir. Bu çalışmada her iki gruptaki hastaların yaş, gravida, parite, abortus değerleri kontrol grubuna göre anlamlı olarak daha yüksek bulunmuştur.
Çalışmanın sonuçlarındaki WBC, PLT ve MPV değerlerindeki literatür ile farklıığın sebebi, demografik verilerdeki bu farklılık olabilir. Bir başka neden ise EG'te olduğu gibi acil kabul edilen durumlarda kan numuneleri hızlı çalışılmasıdır. Ancak çalışmamızda EG olan grupta tüm kanların acil çalışılması veya iki saat içerisinde çalışılması gibi bir standardizasyon yapılamadı. Hastaların bir kısmında kan numuneleri acil çalışıırken, bir kısmında ise iki saate analiz edildi. Bununla birlikte kontrol grubu olarak tanımlanan hastalarda kan numuneleri ortalama iki saatte analiz edilmektedir. MPV değerleri EDTA ile antikoagüle edilmiş numunelerdeki zamana göre değişir ve trombosit morfolojisindeki santrifüj süresi ve EDTA kaynaklı değişiklikler, MPV'de dalgalanmalara neden olabilir. Yani MPV değerlerinin EG grubunda düşük bulunması EDTA'lı tüpteki kalma süresi ile ilişkili olabilir.

Bu çalışmada sağlıklı gebeler ile EG'i olan hastalar karşılaştırıldı̆ında NLO ve PLO değerlerinde her iki grup arasında anlamlı fark bulunmadı. Bu çalışmaya göre PLO ve NLO değeri EG'i saptamada etkili bir tanı testi olmayabilir. Yapılan bir çalışmada MTX yapılan EG'lerin 1., 4. ve 7 günlerindeki NLO değerlerindeki değişimine bakılmış ve NLO'nun tek doz MTX tedavisinin başarısını göstermede yeterli olduğu, ancak NLO seviyelerinin 4. ve 7. günler arasında $\% 15$ oranında $\beta$-hCG azalması protokolü kadar başarılı olmadığı bulunmuştur. Aynı çalışmada PLO MTX tedavisinin başarısını değerlendirmede anlamlı bulunmamıştır (17). Bu çalışmada EG grubu ile sağıklı gebeler grubu arasındaki NLO değerlerinde anlamlı fark izlenmese de NLO, EG grubunda değersel olarak sağıklı gebelere göre daha yüksek izlenmiştir. Bu durum altta yatan patogenezin inflamasyon ile ilişkili olabileceğini destekleyebilir. Ayrıca bu çalışmada $\beta$-hCG değerleri karşılaştııımamıştı fakat trofoblastik invazyon sonucu ortaya çıkan $\beta$-hCG düzeylerindeki farklılık sonuçlarımızı etkilemiş olabilir. Çünkü tubal invazyonun inflamasyona sebep olabilmesi, tubal serozayı rüptüre etmesi veya intrauterin gebeliklerde $\beta$-hCG düzeylerindeki artışın farklı olması çalışmanın sonuçlarına yansımış olabilir.

Yakın zamanda yapılan bir çalışmada MTX yapılan ve cerrahi uygulanan hastaların Hgb, MCV, WBC, PDW, PLO, NLO değerleri karşılaştırımıştır. MTX grubunda RDW, MPV anlamlı olarak yüksek iken, gruplar arasında WBC, $\mathrm{Hgb}, \mathrm{MCV}, \mathrm{PLT}, \mathrm{PDW}, \mathrm{PLO}, \mathrm{NLO}$ açısından istatistiksel olarak anlamlı fark bulunmamıştır (18). Çalışmanın sonucunda MPV değerinin MTX tedavisi ile ilişki olduğu bildirilmiştir. Bu çalışmada MTX başarılı ve MTX başarısız gruplarda MPV, WBC, PLT, NLO ve PLO değerleri arasında fark izlenmedi.

Yine son zamanlarda yapılan bir çalışmada tubal rüptüre EG ile non-tubal rüptüre EG arasında PLO ve NLO değerlerine bakılmış ve rüptür olan EG'lerde NLO ve PLO değerleri daha yüksek bulunmuştur (19). Aynı çalışmada NLO ve PLO'nın seviyelerinin rüptüre EG'lerdeki $\beta$-hCG sonuçları 
ile korele olduğu görülmüştür (19). Her ne kadar bu çaIışma ana hipotez olarak önceki bahsedilen çalışma ile ile farklı olsa da çalışmamızda da PLO ve NLO seviyelerinin her iki grup arasında farkı olmadığı görüldü. Bu durum EG tanısının konmasında etkili bir yöntem olmayabilir. Çalışmamızın sonuçlarının literatürdeki benzer yazılardan farklı çıkmasının nedeni, hem çalışmamızdaki hasta sayısının daha fazla olması, hem de demografik verilerdeki anlamlı farkın PLO ve NLO fizyolojisini etkilemesi sonucu olabilir. Bu çalışmadaki kısıtıılık çalışmanın dizaynının retrospektif planlanması ve her laboratuvarın ölçüm ve bekleme sürelerinin değişken olmasıdır. Çünkü bu testlerin ölçümleri sıcaklık, saklama koşulları ve ölçüme kadar geçen süre gibi çevresel ve laboratuvar koşullarından etkilenebilir. Ayrıca hastalardan tek seferlik hemogram alınmasının diğer bir limitasyon nedeni olduğunu düşünmekteyiz. Bu durum değerlerimizi etkilemiş olabilir. Fakat çalışmaya çok sayıda hasta dahil edilmesi ve kontrol grubundaki gebelerin miada kadar takip edilip ek hastalığı olanların çalışmadan çıkarılması bu çalışmayı güçlü kılmaktadır. Böylece ilerleyen gebelik haftalarında ortaya çıkabilecek kötü gebelik sonuçlarının çalışmamızı etkilemesi önlenmiştir.

\section{Sonuç}

EG'i öngörmede hemogram parametrelerinden sadece MPV değeri anlamlı bulundu. Bu çalışmada NLO ve PLO değerleri EG tanısını öngörmede etkili bulunmadı. EG tanı ve tedavi protokollerinde hemogram, NLO ve PLO değerleri olası ilişkileri araştırmak için daha geniş hasta gruplarının inceleneceği prospektif çalışmalara intiyaç vardır.

Etik Onam: Bu çalışmanın etik kurul onamı Sağlık Bilimleri Üniversitesi Bakırköy Dr. Sadi Konuk Eğitim ve Araşıırma Hastanesi'nden (etik kurul no: 2017/415) alındı.

\section{Kaynaklar}

1. Yalçin Bahat $P$, Turan $G$, Aslan Çetìn $B$, Polat I. Comparison of laparoscopy and laparotomy in surgical treatment of ectopic pregnancies: $A$ 6-year experience at a tertiary center. Turkiye Klin Jinekoloji Obstet. 2018;28(2):60-4.

2. Bouyer J, Coste J, Shojaei T, Pouly JL, Fernandez H, Gerbaud L et al. Risk factors for ectopic pregnancy: A comprehensive analysis based on a large case-control, population-based study in France. Am J Epidemiol. 2003;157(3):185-94.

3. Shaw JLV, Dey SK, Critchley HOD, Horne AW. Current knowledge of the aetiology of human tubal ectopic pregnancy. Hum Reprod Update. 2010;16(4):432-44.

4. Peker N, Yaman Tunç S, Sak S, Karaçor T, Başaranoğlu S, Gül T. Ektopik Gebelik Olgularında Gebelik Haftasına Göre Tedavi Yaklaşımlarının Retrospektif Değerlendirilmesi. Zeynep Kamil Tıp Bülteni. 2017;48(1).

5. Turgut A, Sak ME, Özler A, Soydinç HE, Karaçor T, Gül T. Alteration of peripheral blood cells in tubal ectopic pregnancy. Ginekol Pol. 2013;84(3):193-6.

6. Ulkumen BA, Pala HG, Calik E, Koltan SO. Can mean platelet volume and platelet distrubition width be possible markers for ectopic pregnancy and tubal rupture? (MPV and PDW in ectopic pregnancy). Pakistan J Med Sci. 2014;30(2):352-5.

7. Vagdatli E, Gounari E, Lazaridou E, Katsibourlia E, Tsikopoulou F,
Labrianou I. Platelet distribution width: A simple, practical and specific marker of activation of coagulation. Hippokratia. 2010;14(1):28-32.

8. Li Z, Yang F, Dunn S, Gross AK, Smyth SS. Platelets as immune mediators: Their role in host defense responses and sepsis. Thromb Res. 2011;127(3):184-188.

9. Practice Committee of the American Society for Reproductive Medicine. Medical treatment of ectopic pregnancy: a committee opinion. Fertil sterility,. 2013;100(3):638-644.

10. Stulberg DB, Cain LR, Dahlquist I, Lauderdale DS. Ectopic pregnancy rates in the Medicaid population. Am J Obstet Gynecol. 2013;208(4):274.e1-274.e7.

11. Menon S, Colins J, Barnhart KT. Establishing a human chorionic gonadotropin cutoff to guide methotrexate treatment of ectopic pregnancy: a systematic review. Fertil Steril. 2007;87(3):481-484.

12. Rausch ME, Barnhart KT. Serum biomarkers for detecting ectopic pregnancy. Clin Obstet Gynecol. 2012;55(2):418-23.

13. Mannaerts D, Heyvaert S, De Cordt C, Macken C, Loos C, Jacquemyn Y. Are neutrophil/lymphocyte ratio (NLR), platelet/lymphocyte ratio (PLR), and/or mean platelet volume (MPV) clinically useful as predictive parameters for preeclampsia? J Matern Neonatal Med. 2019;32(9):1412-9.

14. Eskicioğlu F, Özdemir AT, Turan GA, Gür EB, Kasap E, Genç M. The efficacy of complete blood count parameters in the diagnosis of tubal ectopic pregnancy. Ginekol Pol. 2014;85(11):823-7.

15. Gencdal S, Aydogmus H, Gencdal NK, Destegul E, Ekmekci E. Evaluation of the Neutrophil-Lymphocyte Ratio and Platelet-Lymphocyte Ratio in Patients With Ectopic Pregnancies. J Clin Gynecol Obstet. 2019;8(3):81-4.

16. Yuri Gasparyan A, Ayvazyan L, P. Mikhailidis D, D. Kitas G. Mean Platelet Volume: A Link Between Thrombosis and Inflammation? Curr Pharm Des. 2011;17(1):47-58.

17. Kanmaz AG, Inan AH, Beyan E, Budak A. Role of various complete blood count parameters in predicting the success of single-dose methotrexate in treating ectopic pregnancy. Pakistan $\mathrm{J}$ Med Sci. 2018;34(5):1132-36.

18. Akkaya H, Uysal G. Can hematologic parameters predict treatment of ectopic pregnancy? Pakistan J Med Sci. 2017;33(4):937-42.

19. Kan Ö, Gemici A, Alkilic A, Cetindag EN, Cakir C et al. The Effect of Preoperative Neutrophil-To-Lymphocyte Ratio and Platelet-To-Lymphocyte Ratio on Predicting Rupture Risk in Tubal Ectopic Pregnancies. Gynecol Obstet Invest. 2019;84(4):378-82 